\title{
Huir del Amor. Emblemática y paisaje en una nueva pintura de Otto van Veen
}

\author{
Fleeing Love. The emblems and landscape of a new painting by Otto van Veen
}

\section{Jahel Sanzsalazar ${ }^{1}$}

\begin{abstract}
Resumen: En el anonimato durante siglos y de gran tamaño, la pintura objeto de este estudio se restituye a Otto van Veen. Por su composición, modelos y estilo se vincula con su producción conocida, y se compara, entre otras obras, con Hércules y la Hidra del museo de Budapest y con el Cristo muerto de la iglesia de Sint-Waudru de Mons, Bélgica. El asunto se asocia con la emblemática a la que Van Veen se dedicó activamente. Los versos de las Elegías de Propercio en el margen inferior del lienzo reflejan el profundo conocimiento de la literatura clásica resultante de la formación humanista del pintor, al tiempo que advierten contra la inutilidad de huir del amor. Un mensaje moral asido en los principios del Neoestoicismo fundado por su gran amigo Justus Lipsius. A propósito de la ejecución del paisaje, se excluye la posibilidad de la intervención de otra mano, dadas su inclinación al género y la ausencia de evidencias documentales de tal tipo de colaboración. El hallazgo de esta pintura viene a sumarse a la relativamente limitada producción que del maestro se conoce en España hasta la fecha.
\end{abstract}

Palabras clave: Otto van Veen (Vaenius), Pintura flamenca, siglo XVI, Emblemática, Paisaje, Jan Snellinck, Franchoys Borsse, Rubens.

Abstract: Anonymous for centuries a major canvas is attributed to Otto van Veen on the basis of a body of research. By its composition, models and style the painting is associated with his recognised oeuvre; and further compared to the Hercules and the Hydra in Budapest Fine Arts Museum, and The dead Christ from the church of Saint-Waudru in Mons, Belgium, among others. The subject of the painting is related to the emblem books that Van Veen actively produced. The verses of Propertius' Elegies quoted at the bottom right of the canvas reflect the deep knowledge of classical literature resulting from the painter's humanistic learning, whilst warning against the futility of escaping love. A moral message attached to the ideals of Neostoicism founded by his close friend Justus Lipsius. Regarding the execution of the landscape, the possibility of the intervention of another hand is excluded given Van Veen's inclination to the genre, and the lack of documented evidence of such

\footnotetext{
${ }^{1}$ orcid.org/ 0000-0001-8564-9703
}

(C) 2017 Philostrato. Revista de Historia y Arte 
collaborations. The discovery of this painting adds to the relatively limited production of the master known in Spain to date.

Key Words: Otto van Veen (Vaenius), Flemish Painting, 16th Century, Emblems, Landscape, Jan Snellinck, Franchoys Borsse, Rubens.

Recibido: 07/04/2017



e impone en el primer plano de este lienzo de enormes dimensiones $(162 \times 236 \mathrm{~cm})$ la monumental figura de un jinete a caballo, corriendo a galope y cuesta arriba, en un paisaje fluvial de suaves colinas (fig. 1). Parece querer huir despavorido mientras, en la grupa del caballo, un cupido intenta detenerlo, asiéndolo con fuerza por los cabellos y el brazo. El caballero vuelve el rostro hacia atrás al tiempo que su mano rendida, abierta y crispada, destaca con nitidez sobre el fondo azul del cielo. A la izquierda y en segundo plano, por un sendero a la orilla del río, se acercan en fila dos parejas que, asidos del brazo, flanquean a una muchacha que camina sola. Cae sobre la cabeza de ésta otro cupidillo, arco tensado, dispuesto a lanzar su flecha. Bajo un vasto cielo que se torna plomizo, se abre entre dos árboles la inmensidad de un paisaje hasta las montañas iluminadas del horizonte, con la etérea interferencia de otra pareja que cruza el puente del río. En el margen inferior izquierdo se leen en un recuadro dos versos en latín: "QVO FVGIS, AH DEMENS. NVLLA EST FUGA: TV LICET VSQUE. / AD TANAIM FUGIAS, VSQVE SEQVETUR AMOR".

Considerado anónimo hasta hoy, el lienzo concuerda en composición, modelos, calidad y estilo con Otto van Veen (Leiden, 1556 - Bruselas, 1629), pintor de formación humanista, conocido para el gran público por haber sido el maestro de Peter Paul Rubens ${ }^{2}$. Fue grande su contribución a la formación del gran genio flamenco, que siguió su estilo y colaboró con él antes de partir a Italia, lo que provoca aún discusiones en cuanto a la autoría de algunas obras $^{3}$. Aunque falto del genio de su discípulo, Otto van Veen no sólo dotó a Rubens de una sólida formación técnica; también le transmitió -igual que transmite en esta pintura- su profundo conocimiento de la cultura clásica y de los libros ${ }^{4}$, el amor indeleble por la Antigüedad de la que siempre sacaría partido. Pero mientras Rubens fue el protagonista de la revolucionaria transición al Barroco, Van Veen permaneció fiel a un manierismo tardío como

\footnotetext{
2 Hans Vlieghe, "Rubens and Van Veen in contest: A marginal note", en Ars Auro Prior, Studia Ioani Bialostocki Sexagenario Dedicata, (Varsovia, 1981), pp. 477-482.

3 En su correspondencia con Rogier de Piles, Philippe Rubens se expresa así a propósito del estilo de juventud de su tío: "avant son voyage en Italie ils avoient quelque ressemblance avec ceux d'Octave van Veen, son maistre"; véase Charles Ruelens, "La vie de Rubens par Roger de Piles", Bulletin Rubens, II, (1885), p. 166. Muy discutidas han sido la Lamentación del Louvre, Adán y Eva de la Rubenshuis, la Alegoría de la juventud del museo de Estocolmo y la Batalla de las amazonas de la galería de Potsdam.

4 Justus Müller-Hofstede, "'Ut Pictura Poesis': Rubens und die humanistische Kunsttheorie", Gentse bijdragen tot de kunstgeschiedenis, 24, (1976-1978), pp. 171-189.
} 
ilustre representante de una generación italianizante de la gran pintura de historia de la escuela de Amberes ${ }^{5}$.

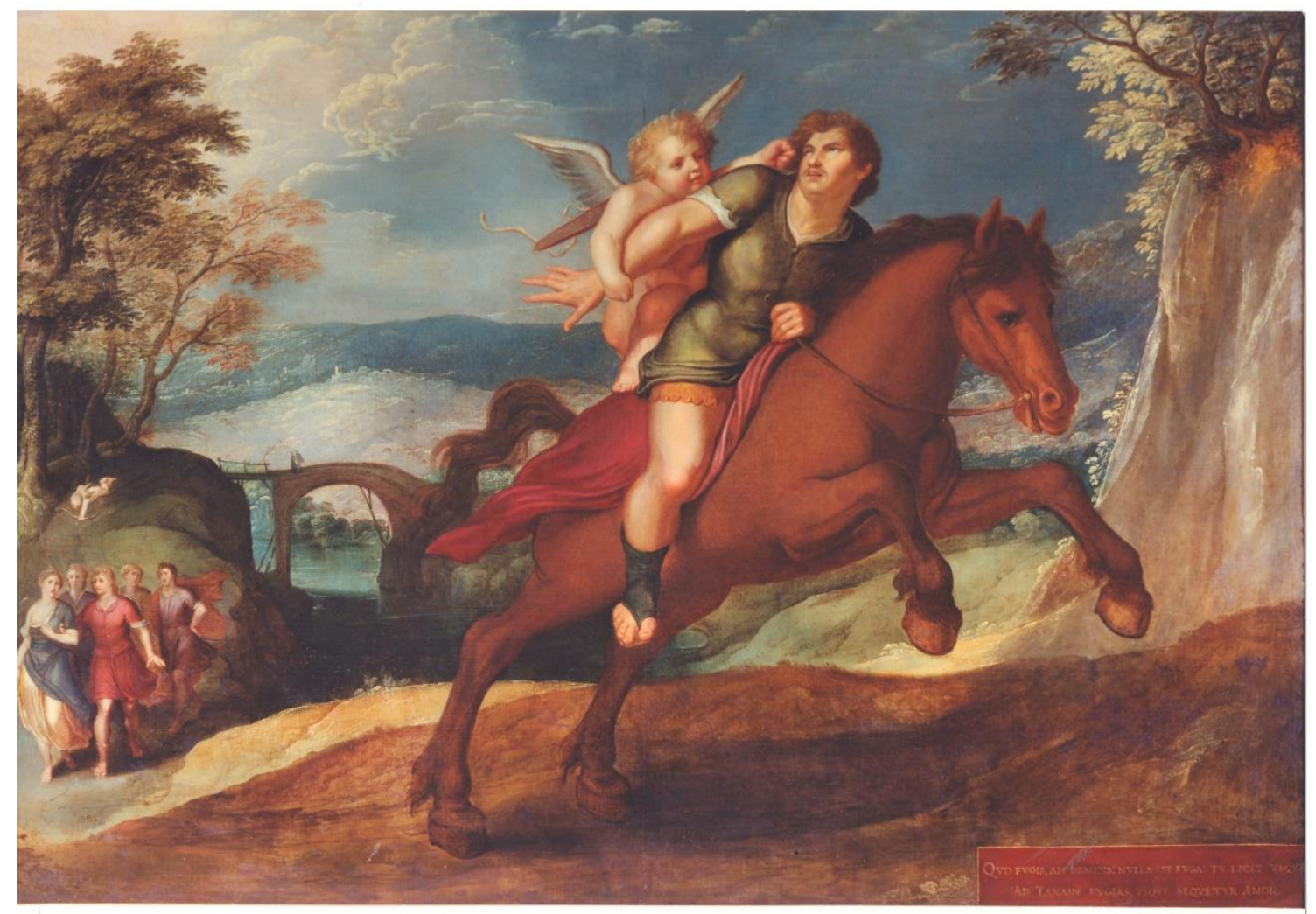

Fig. 1. (Aquí atribuido a) Otto van Veen. ¿Huir del amor ? Lienzo, 162 x $236 \mathrm{~cm}$. Navata, Gerona, colección

Casamor

Es característico su estilo estático, rígido y algo ingrato, las figuras de formas sólidas y proporciones heroicas que parecen detenidas en el espacio, la construcción por masas de colores lisos y claros, de colorido afín a Correggio, la iluminación artificiosa, y la composición teatral, de grandes gestos. La imagen está concebida para ser vista desde abajo, de ahí su acusado aspecto monumental. Las siluetas de las tres parejas que caminan, graciosas y danzantes, se reencuentran en los diseños de Otto Van Veen. Su fisionomía se recuerda entre las mujeres del fondo de la abigarrada reunión en el Miles Christianus ${ }^{6}$. Particularmente típico es el modelo del caballero, de canon corto y achaparrado, de formas vigorosas, llenas y pesadas; y la iluminación que hace resaltar algunas partes de su cuerpo vestido a la romana. El modelo del rostro se repite de manera textual en Hércules y la Hidra del museo de Budapest (fig. 2) ${ }^{7}$, ambos semejantes al ángel que

${ }^{5}$ Véase al respecto Julien Vervaet, "Mannerism and the Italian influence in sixteenth-century Antwerp", Apollo, Vol. CV, No.181, (March 1977), pp. 168-175.

${ }^{6}$ Lienzo, 159 x $116 \mathrm{~cm}$. Con inscripción: "Miles Christianus contra peccata mortalia pugnans coronam recipit ...". Véase Hans Ost, "Unbekannte Werke von Otto van Veen", Wallraf-Richartz-Jahrbuch, LXVIII, (2007), pp. 279-294. Posteriormente en Colonia (Van Ham Kunstauktionen), 15/05/2015, lot 505; Zurich (Koller), 18/09/2015, lot 3032; Colonia (Van Ham), 18/11/2016, lot 517.

7 Lienzo, $132 \times 136 \mathrm{~cm}$. Budapest, Museo de Bellas Artes, Inv. 78.2. Véase Ember Ildiko, "Drei Flämische Allegorien im Museum der Bildende Künste in Budapest", Annales de la Galerie Nationale Hongroise, (1991), pp. 131-139, fig. 1. En el Rijksmuseum de Ámsterdam hemos visto un grabado anónimo basado 
sostiene el cuerpo de Jesús en el Cristo muerto de la iglesia belga de SintWaudru de Mons, con el mismo cuello robusto y rostro suplicante, los ojos dirigidos hacia arriba y la boca entreabierta (fig. 3) ${ }^{8}$. Análogos son también los modelos del panel central del tríptico de la iglesia de San Gumaro de Lier $^{9}$ y de un Salvator Mundi aparecido estos últimos años en el comercio ${ }^{10}$. Son modelos que causan en Rubens un innegable impacto, perceptible aún en las primeras obras que ejecuta al llegar a Roma, como el Éxtasis de santa Helena de la catedral de Grasse (1601) y la Lamentación de la Galería Borghese, cuyas figuras están todavía impregnadas del estilo de su maestro.

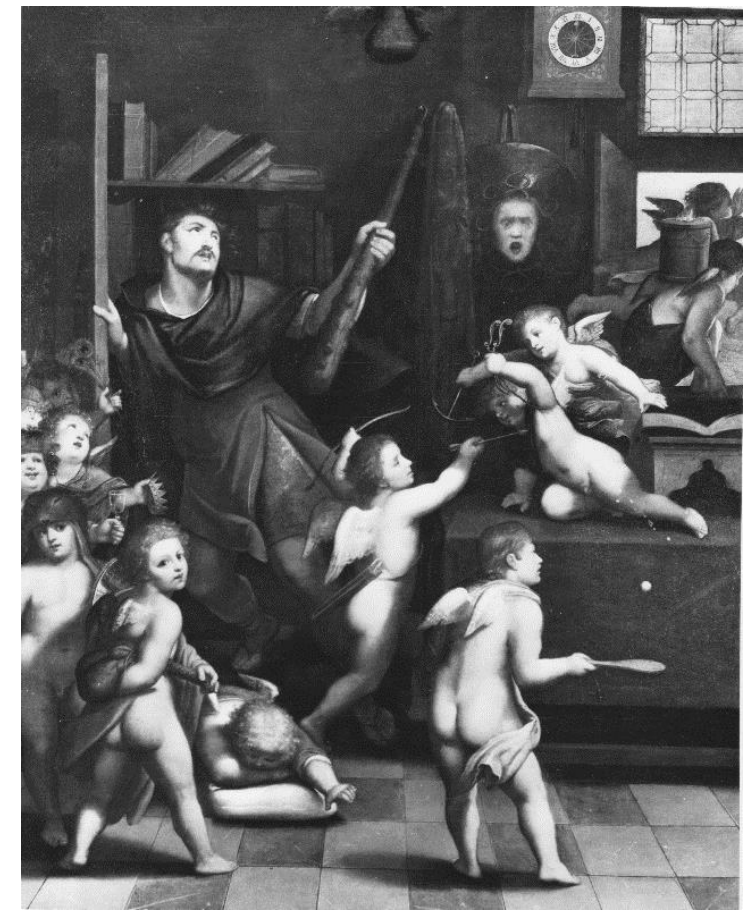

Fig. 2. Otto van Veen. Hércules y la Hidra. Lienzo, 132 x $136 \mathrm{~cm}$. Budapest, Museo de Bellas Artes (Inv. 78.2). (C) Fine Arts Museum, Budapest

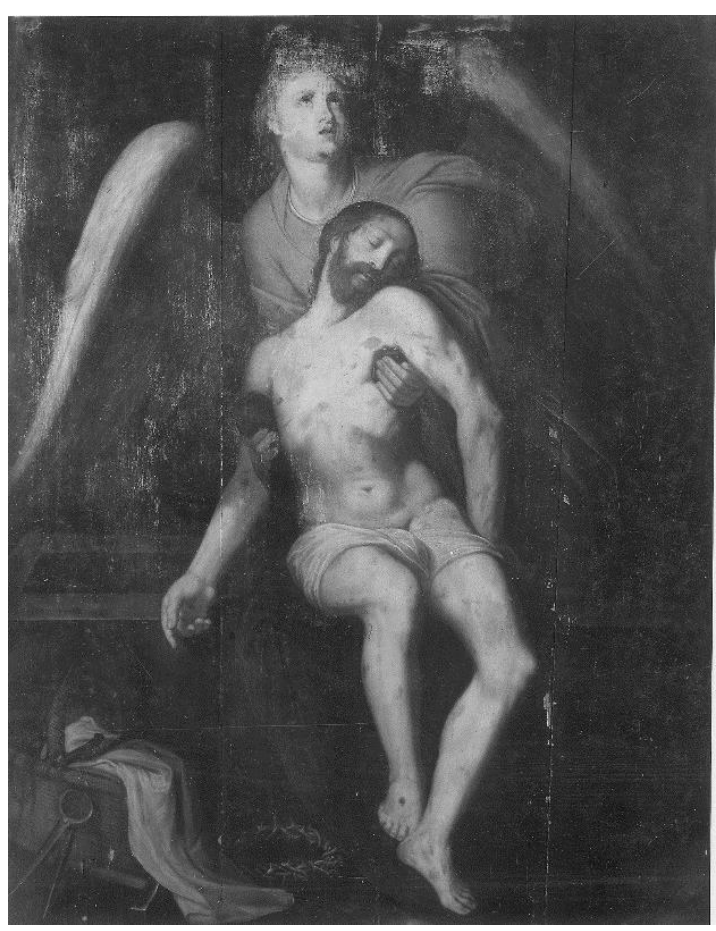

Fig. 3. Otto van Veen. Cristo muerto sostenido por un ángel. Tabla, 124 x $97 \mathrm{~cm}$. Mons, iglesia de Sint-Waudru

Suficientes ejemplos de concesión al paisaje encontramos en la producción de Otto van Veen como para excluir una hipotética colaboración de otra

en esta pintura y publicado por Peter de Jode (Inv. RP-P-1904-3695); F.W.H. Hollstein, Heer - Kuyl, p. 204, cat. 95.

8 Tabla, $124 \times 97 \mathrm{~cm}$. La pintura necesitaba una restauración que ya reclamaba Julius Held en el momento de su identificación, al tiempo que la databa de antes de la partida de Rubens a Italia. Julius Held, "The authorship of three paintings in Mons", Bulletin des Musées Royaux des Beaux Arts de Belgique, no 3 (1953), pp. 100-102, 104, fig. 3. Müller-Hosftede ve una obra cronológicamente decisiva en la evolución del pintor. Justus Müller-Hofstede, "Zum Werke des Otto van Veen, 1590-1600", Bulletin des Musées Royaux des Beaux-Arts de Belgique, VI, (1957), p. 136, fig. 5. Nicole Walch señala el robo de la misma en julio de 1980. Nicole Walch, "Deux eaux-fortes anonymes en relation avec le tableau d'Otto van Veen Le Christ mort soutenu par un ange", en Francine de Nave (dir.), Liber Amicorum Leon Voet, (Antwerpen, $1985)$, p. 629, nota 2.

9 Tabla, 192 x $151 \mathrm{~cm}$. Lier, Kerk Sint-Gummarus. Cliché KIK-IRPA: M272572.

10 Lienzo, $50 \times 39 \mathrm{~cm}$. Londres (Christie's), 2/07/1997, lot 306 (circle of Hendrik de Clerck); Stockholm (Bukowski), 24/11/1999, lot 461 (Otto van Veen); Viena (Dorotheum), 22/03/2001, lot 132 (Otto van Veen); New York (Christie's), 17/06/2004, lot 4 (Otto van Veen). 
mano, como en ocasiones se ha sugerido ${ }^{11}$. El paisaje se hace presente tanto en sus grandes retablos (véase la Resurrección de Lázaro de la Catedral de Amberes y la predela del Retablo de San Andrés) ${ }^{12}$; como en los grabados (la serie de Santo Tomas de Aquino de 1610 o los de Antonio Tempesta en $1612)^{13}$ y en las pinturas de pequeño formato (la serie de las Guerras de los Batavos y los Romanos) ${ }^{14}$. En Hércules personificando a Flandes en la Tregua de los doce años (fig. 4) ${ }^{15}$, pequeña tabla de colección privada española fechada en 1612, incluye un paisaje de gran delicadeza. Deriva del emblema Culmen honoris lubricum (la cumbre de la honra es peligrosa) de la Emblema-

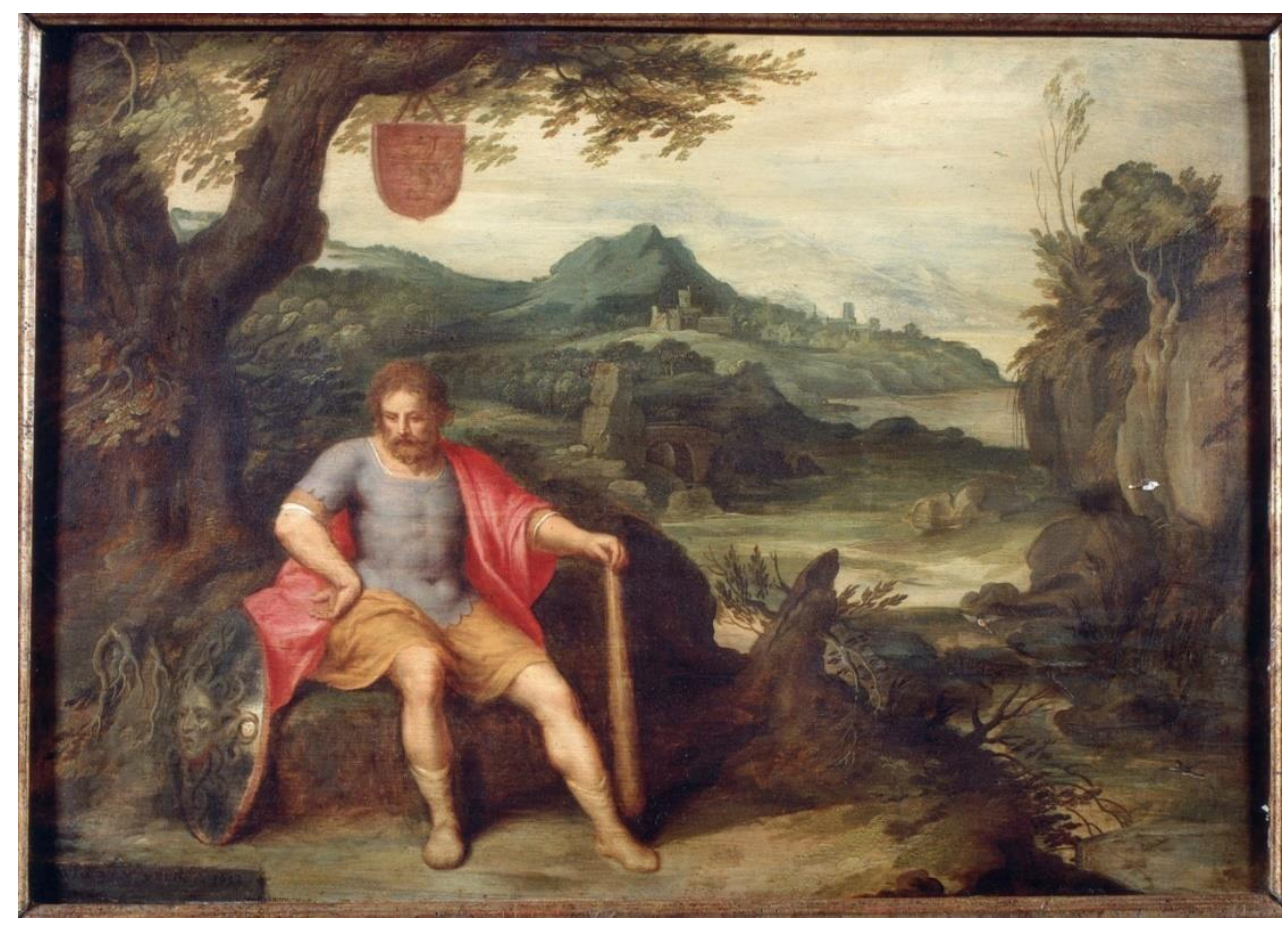

Fig. 4. Otto van Veen. Hércules personificando a Flandes en la Tregua de los doce años. Tabla, 37,5 x 53,5 cm. Firmada y fechada: "OCTAVIO VAN VEEN.1612”. Madrid, colección particular

ta Horatiana (1607), donde recurre a los mismos efectos, con un puente cruzando un río serpenteante en la perspectiva central (fig. 5). En Virtus inmortalis vemos una dinámica semejante de la figura y del paisaje, con un terreno de ondulación similar ${ }^{16}$. En el Paisaje panorámico firmado y fechado

\footnotetext{
11 Véase nota 33 infra.

12 Müller-Hosftede, "Zum Werke des Otto van Veen...", p. 141, fig. 8, p. 151, fig. 13.

${ }^{13}$ Representa La madre de Santo Tomas partiendo para Nápoles, por Cornelis Boel según Otto van Veen. Otto van Veen, Vita D. Thomae Aqvinatis. Antwerpen, voor O. van Veen, 1610, n 6; F.W.H. Hollstein, Boekhorst - Brueghel, p. 7, cat. 10-22.

14 Tabla, 38 x 52 cm. Ámsterdam, Rijksmuseum, Inv. SK-A-427-425-427, 431, 432.

15 Tabla, 37,5 x 53,5 cm. Firmada y fechada: "OCTAVIO VAN VEEN.1612"; Ámsterdam (Christie's), 9/05/2001, lot 104; Ídem, 4/09/2001, lot 390; Madrid, colección privada.

${ }^{16}$ Inemie Gerards-Nelissen, "Otto van Veen's Emblemata Horatiana", Netherlands Quarterly for the History of Art, vol 5, 1-2, (1971), p. 49.
} 
en 1586 (fig. 6 ) $^{17}$-único testimonio que conocemos de su concesión exclusiva al género- anida un sentimiento estético que no es ajeno al de la pintura que estudiamos, una análoga concepción espacial, una visión panorámica con perspectiva en fuga central y línea de horizonte alta.

De otra parte, es poca la constancia documental que existe de la colaboración de Otto van Veen con otros pintores. Al margen de Rubens y Brueghel -con los que se dice ejecutó una representación del monte Parnaso $^{18}$ - sabemos que en 1597 trabajó con Jan Snellinck (1548-1638), reci-

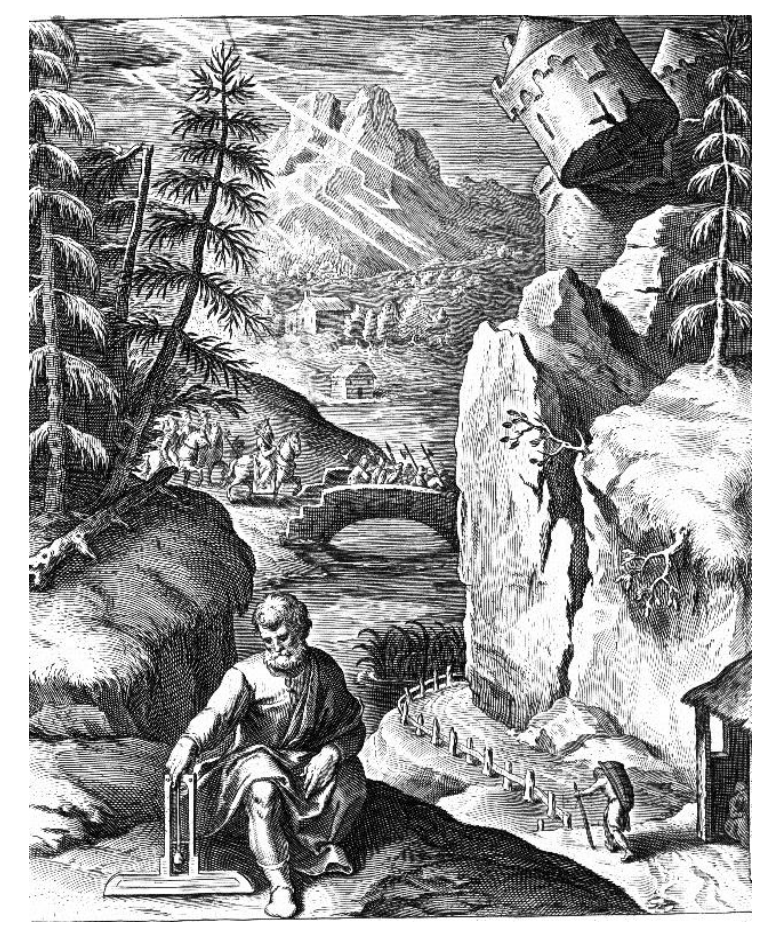

Fig. 5. Culmen honoris lubricum. Emblema 46 de la Emblemata Horatiana de Otto van Veen (1607).

biendo pago por los diseños (hoy perdidos) en los que éste se basó para los cartones de los tapices de las Batallas del archiduque Alberto, que fueron tejidos en el taller de Maarten van Reymbouts II en Bruselas y conserva hoy (en parte) el Palacio de El Pardo de Madrid ${ }^{19}$. El mismo tapicero se sirvió de cartones de Snellinck para otra serie dedicada a Ambrosio Spinola ${ }^{20}$. No obstante, y como bien reivindica la inscripción ("IOANNES SNELLINCX. /

\footnotetext{
17 Cobre, 44,5 x 58 cm, firmado y fechado: "Otto Veni... f 1586". Londres (Christie's), 10/12/1993, lot 206. ${ }^{18}$ Citada en 1642 en el inventario del marchante Nyt; véase F. J. Van den Branden (dir.), "Collection de tableaux à Anvers", Bulletin des archives d'Anvers / Antwerpsch Archievenblad, XXI, (1883), p. 342.

19 Franz Joseph Peter van den Branden, Geschiedenis der Antwerpsche Schilderschool, (Antwerpen: Buschmann, 1883), pp. 406-407; Marcel de Maeyer, "Otto Vaenius en de tapihjtenreeks De Veldslagen van aartshertog Albrecht", Artes Textiles, II, (1955), p. 105, nos. 1-5; Concha Herrero Carretero, en Tapestry in the Baroque: Threads of Splendor, (Thomas P. Campbell, ed.), (New York, Metropolitan Museum y Madrid, Palacio Real, 2007-2008), pp. 54-59, cat. 6.

20 Londres (Sotheby's), 29/10/2003, lots 173-174.
} 
PICTOR HVMANORVM FIGURARVM ANTVERPIÆE") ${ }^{21}$ que se lee al pie de su retrato grabado por Pieter de Jode según Van Dyck ${ }^{22}$, Jan Snellinck era pintor de figuras. No ha de confundirse con su hijo Andries Snellinck (1587-1653), que sí era paisajista ${ }^{23}$.

Con Otto Vaenius, Jan Snellinck comparte un lenguaje pictórico común que se ve en las escasas obras conservadas que con seguridad son de su mano ${ }^{24}$. Al margen de las pinturas que se documentan a su nombre en su propia testa-

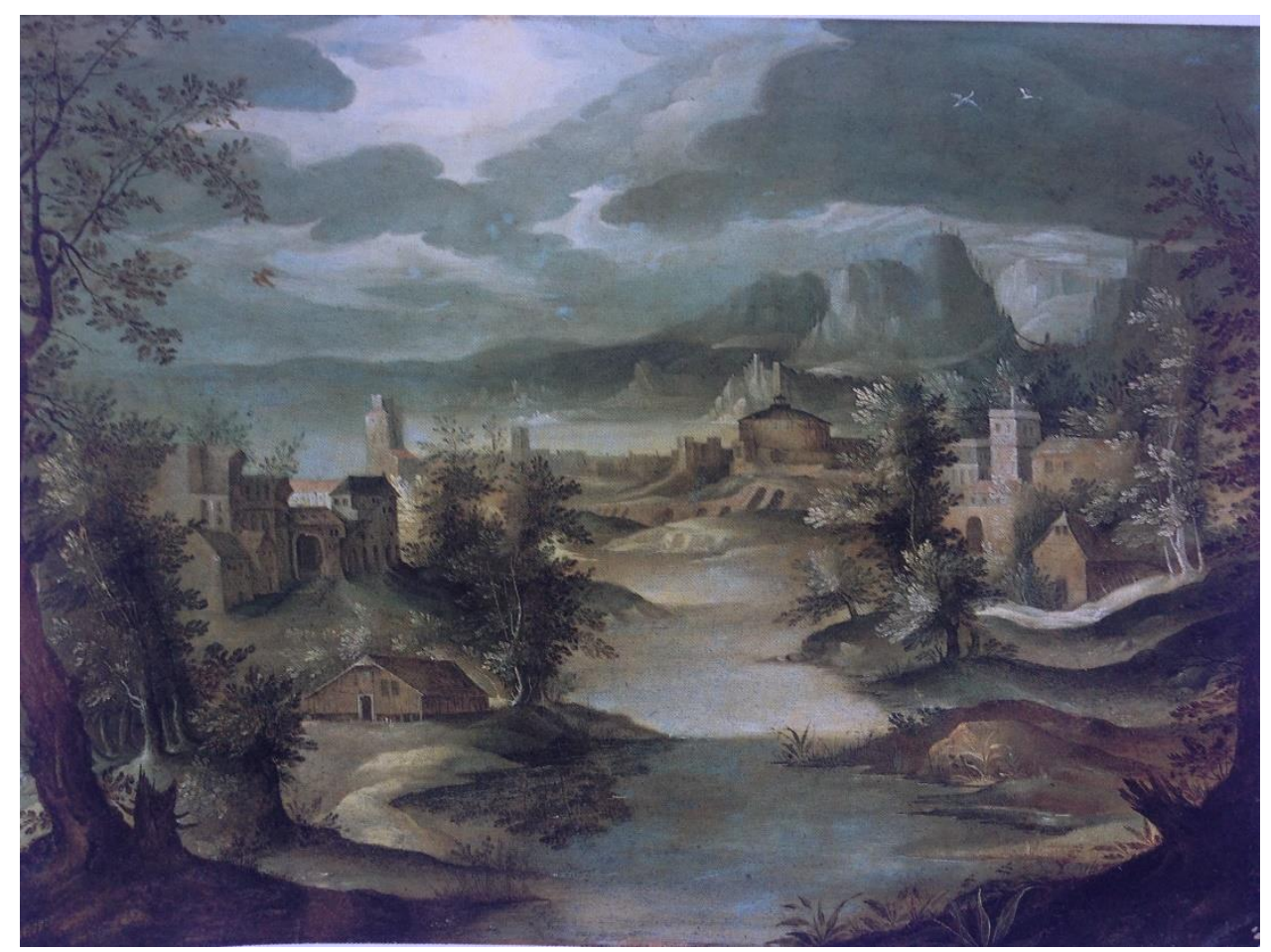

Fig. 6. Otto van Veen. Paisaje panorámico. Cobre, 44,5 x $58 \mathrm{~cm}$., firmado y fechado: "Otto Veni... f 1586". Paradero actual desconocido.

\footnotetext{
${ }^{21}$ Con la inscripción: "Ant. van Dyck pinxit. / Pet. de Iode ssculp. Cum privilegio"; véase The New Hollstein, Ant. van Dyck, vol II, nº 91.

22 Véase el dibujo de Van Dyck. Horst Vey, Die Zeichnungen Anton Van Dycks, (Bruxelles, 1962), n² 245. Figura sobre una mesa en el Retrato de Martin Ryckaert y su familia. Bernadette van Haute, David III Ryckaert: A Seventeenth-Century Flemish Painter of Peasant Scenes, (Turnhout: Brepols, 2000), p. 158.

23 Katlijne van der Stighelen, "De (atelier-)bedrijvigheid van Andries Snellinck (1587-1653) en Co", Jaarboek van het Koninklijk Museum voor Schone Kunsten Antwerpen, (1989), pp. 303-341.

${ }^{24}$ Cristo en la Cruz entre los ladrones (Tabla, 272 x $229 \mathrm{~cm}$. Firmada y fechada: "J. VAN SNELLINCK. 1.5.9.7."), Antwerpen, Koninklijk Museum voor Schone Kunsten, Inv. 334; Retablo de la Catedral de Malinas, cuya tabla central con la Ascensión de Cristo entre San Pedro y San Pablo está firmada y fechada "I. SNELLINCX. F. 1601". Justus Müller-Hofstede, "Abraham Janssens: Zur Problematik des flämischen Caravaggismus", Jahrbuch der Berliner Museen, 13 (1971), p. 216. Dibujo a tinta y aguada sobre papel, $191 \times 283 \mathrm{~mm}$. Ottawa, National Gallery of Canada, inv./cat.nr 17187. Un grabado de Los diez mandamientos ejecutados por Jan Collaert I según sus diseños. Ann Diels y Marjolein Leesberg, The new Hollstein, Dutch and Flemish Etchings, Engravings and Woodcuts 1450-1700, The Collaert Dinasty, (2006), vol. II, p. $215, \mathrm{n}^{\circ} 432$.
} 
mentaría 25 , pensamos que sería el "Snelling" que pintó una Asunción de la Virgen que tuvo Carlos I de Inglaterra ${ }^{26}$, el que introdujo sus figuras en las Cuatro estaciones de Joos de Momper $^{27}$ y al que se refieren otras obras documentadas y sin localizar ${ }^{28}$. Vale la pena destacar las que tuvo el tapicero Jacques Snel ${ }^{29}$, especialmente un órgano con clavicémbalo, porque se dice pintado a tres manos por Vaenius, Snellinck y un tal Franchoys Borsse ${ }^{30}$. Esto demuestra que la colaboración fue más que puntual. El también oscuro Frans Borsse (activo entre 1585-1615) parece, en cambio, haberse dedicado al paisaje ${ }^{31}$, pero no se le conoce en la actualidad obra alguna que nos permita identificar su estilo.

Curiosamente, fueron paisajes con figuras lo que Otto van Veen recomendó desde Flandes para decorar el studiolo de Alessandro Dell'Orsa, secretario del duque de Farnesio en Parma, que recibe noticia de su indagación por los precios abusivos de los pintores que insertaban sus figuras en los paisajes de

${ }^{25}$ Véanse las obras a su nombre en el inventario de bienes de Jan Snellinck I (1638), el de su hijo, Andries Snellinck (1657), y el de su viuda. Erik Duverger, Antwerpse kunstinventarissen uit de zeventiende eeuw, vol. IV, (Brussel, 1989), pp. 185, 186,188; vol. VII, (Brussel, 1993), pp. 299-300.

${ }^{26}$ George Vertue, A Catalogue and Description of King Charles the First's capital collection, (London, 1757), p. 153.

27 Véanse las Cuatro estaciones que se citan en las cuentas de Forchoudt en 1640: "4 Tijden van Momper en Snellins, -deze hebe ick engecockt". Jan Denucé, Exportation d'oeuvres d'art au XVIIe siècle à Anvers. La firme Forchoudt, (Anvers: De Sikkel, 1931), p. 41 C.

28 La Reconciliación de Jacob y Esau. Tabla, 58 x $47 \mathrm{~cm}$. Firmada: "J. Snellincx de Oude". Berlin (N. Adalbert), 7-II-1928, lot 58; 26 lienzos con Asedios de ciudades y 7 de las Maravillas del mundo: "Jan Snellincx ... ghemaect heft sevenentwintich schilderyen op doeck oliverwe Belegeringhen van Steden ende Seven Wonderen des Werelts...", documento de 1619. Duverger, Antwerpse kunstinventarissen, vol. II, p. 78, $\mathrm{n}^{\circ} 331$; Nueve pinturas de diferentes plazas: "f.319 Nueve Pinturas de diferentes Plazas con marcos azules Jazpeados y media cana dorada de Vara y media de largo y tres qtas de Altto su artifice Juan snelli flamenco a Veinte y quatro ducados cada Una montan Dos mill treçientos y setenta y seis Rs 2376", colección de Juan de Echauz, 1687. Marcus Burke y Peter Cherry, Collections of Paintings in Madrid 16011755. Documents for the History of Collecting: Spanish Inventories 1, (Los Angeles: Maria L. Gilbert, The Provenance Index of the Getty Information Institute, 1997), pp. 810-814; El Arca de Noé: "49. Een kapitaal Stk, verbeeldende daar Noah uyt de Arke gaat mat zyn Familie en allerley Vee, door J. Snellincks", Catalogus van schilderyen. Nagelaaten door wylen den beroemden Kunstschilder Joan Willem Frank. Verkogt den 5. April 1762 in 's Gravenage. Gerard Hoet y Pieter Terwesten, Catalogus of naamlyst van schilderyen ..., ('s Gravenhage: Gaillard, 1770), p. 248.

${ }^{29}$ El Mar rojo: "Een grot stuck schilderye, de Roode Zee, van Hans Snellincx, met fray listen aen", las Bodas de Caná: "Een groot stuck schilderye, de Bruyloft van Cana Gaillilee van Hans Snellincs", Aves: "Een groot stuck schilderye van Hans Snellincx, Vliegerye", Dejad que los niños vengan a mí: "Een groot lanck stuck schilderye van Hans Snellincx, Laet de kinderen tot my comen", Inventario de Jacques Snel, tapicero y tío del pintor Charles de Couwer, testigo del mismo, 1623. Jan Dénucé, De Antwerpsche "Konstkamers": inventarissen van kunstverzamelingen te Antwerpen in de $16 \mathrm{e}$ en $17 \mathrm{e}$ eeuwen, (Amsterdam: De Spiegel 1932), pp. 36-37; Duverger, Antwerpse kunstinventarissen, vol. II, pp. 256-257, 439.

30 "(in de keuken) Een orgel met clavicimbel met veel registers, nachtegael ende andere, het scheel geschildert door Franchoy Borsse, de figurkens van Octavi Venus ende den voet van Snellinck". Duverger, Antwerpse kunstinventarissen, vol. II, pp. 358, 439. La misma colección registra otras piezas a nombre de Borse: "en andere dubbel clavecimbel van Ruckaert (Andries Druckers), eenen Orpheus van Franchoys Borsse, de personagiën van Roelken" y "Een achtsstuyvermaete van Franchoys Borse daer Ons Heer den Blinden sinde maect". Ibidem, pp. 257, 439.

31 "Een Lantschap op doek van Franchoys Borst in lyste", en el inventario de Frans Francken I (1617). Duverger, Antwerpse kunstinventarissen, vol. I, p. 391, no. 247; "Twee Lantschapkens geschildert van Franchoys Bors" en el inventario de Maria Nijs, viuda del marchante Koenraad Vermeulen, 1644. Duverger, Antwerpse kunstinventarissen, vol V, p. 184; " $\mathrm{N}^{\circ} 58$. Les 12 Mois de I'année en 6 diverses pièces" y " $\mathrm{N}^{\circ}$ 51. Un paysage avec l'Europe \& ses nymphes par Spagne et Borse", venta de la colección del pintor Pieter Stevens (1668). Duverger, Antwerpse kunstinventarissen, vol. IX, p. 144-147. 
otros $^{32}$, lo que invita a pensar que era una práctica ajena a él. De otra parte, en las cuentas de los marchantes Forchoudt, se registra un paisaje con emblema de su mano enviado a Viena en 1669 ("n 24. 1 Lantschap amblemada van Octavi Venus") ${ }^{33}$.

Sin motivos se ha puesto en duda la autoría de Otto van Veen en los paisajes de cuatro Alegorías de su mano, procedentes de colección privada española, que se estructuran de manera análoga a nuestra pintura, con un motto inscrito en un recuadro en la parte inferior (fig. 7) ${ }^{34}$. No obstante, el lienzo que nos ocupa es de tamaño excepcional. El pintor está transcribiendo, en grande, la temática de los emblemas por los que fue mundialmente cono-

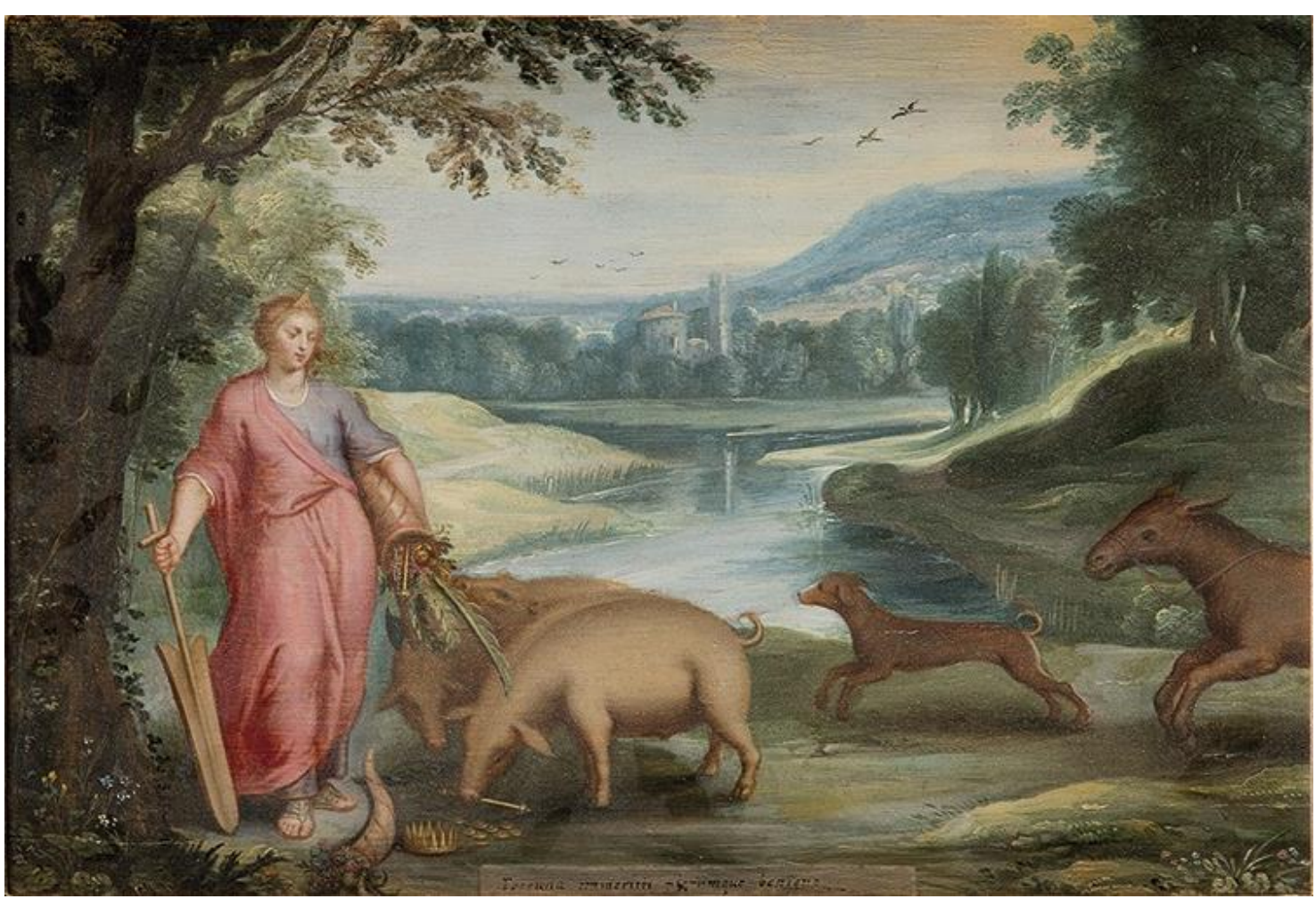

Fig. 7. Otto van Veen, Alegoría, Tabla, 23,5 x 34,5 cm. Paradero actual desconocido

cido. Igual que en los grabados de la Emblemata horatiana o del Amorum emblemata (1608) ${ }^{35}$, combina imagen y palabra con intención moralizante y

\footnotetext{
32 Información que se extrae de dos cartas de Cosimo Masi a Alessandro Dell'Orsa en 1594; véase Giuseppe Bertini, "Otto van Veen, Cosimo Masi and the Art Market in Antwerp at the End of the Sixteenth Century", The Burlington Magazine, 140 (1998), pp. 119-120.

33 Denucé, Exportation, p. 105.

34 (Tablas, 23,5 x 34,5 cm.) Londres (Christie's), 10/12/1993, lot. 212, donde se apunta la colaboración de otro pintor en los paisajes; Madrid, colección privada; Madrid (Fernando Durán subastas), 29/10/2014, lot. 112; Nueva York (Christie's), 29/01/2015, lot. 229.

35 Otto Vaenius, Amorum Emblemata, Antwerpen, 1608; O. Vaenius, Quinti Horatii Flacci Emblemata, (Antwerpen, 1607). Véase Joseph van den Gheyn, Album amicorum de Otto Venius. Reproduction intégrale en facsimilé avec introduction, transcripction, traductions, notes, (Bruxelles, 1911); Gerards-Nelissen, "Otto van Veen's Emblemata...", pp. 20-63; Leonard W. Forster, Die Emblemata Horatiana des Otho Vaenius, (Wolfenbütteler Forschungen, Munich, 1981), pp. 117-128; Santiago Sebastián López, "Teatro moral de la vida humana, de Otto Vaenius: lectura y significado de los emblemas", Boletín del Museo e Instituto Camón Aznar, XIV, (1983), pp. 7-92; Idem, "Lectura crítica de la Amorum Emblemata de Otto Vaenius", Boletín del Museo e Instituto Camón Aznar, XXI, (1985), pp. 5-111; Idem, "La visión
} 
didáctica, para trasmitir reglas de conducta. Como es habitual, Vaenius hace gala de su conocimiento de los autores clásicos al elegir los versos con los que completar el significado de la imagen. En este caso cita a Propercio y sus Elegías, texto compuesto de cuatro libros dedicados a su amada Cintia, en los que el poeta expresa un sentimiento trágico del amor. Vaenius toma para su pintura dos versos de la elegía 30 del libro II, cuya traducción dice así: "¿Adónde huyes, ah insensato? No existe fuga: aunque huyas hasta Tanais, el amor te seguirá hasta allí".

Probablemente el pintor poseería la edición de las Elegías de Willem Canter que editó la imprenta de Christophe Plantin en Amberes en $1569^{36}$, sin duda más accesible que la edición princeps, impresa en Venecia en 1472, o la Joseph Scaliger, editada en París en 1577. Aunque el poema tiene como destinataria a Cintia, el amor del poeta, algunos estudiosos piensan que Propercio habla aquí de él mismo en tercera persona, en una especie de diálogo interior sobre su imposibilidad de escapar del amor ${ }^{37}$. En cualquier caso, el pintor aprovecha la ambigua condición gramatical de "demens" (que no denota sexo), y la aplica a un varón sin necesidad de alterar el texto ${ }^{38}$. Tanais es el nombre griego del río Don, uno de los principales de Rusia y de la ciudad del mismo nombre en el mar de Azov, que se consideraba desde Estrabón la frontera de Europa y Asia; por así decirlo, el fin del mundo ${ }^{39}$.

La elección de un jinete como motivo principal de la escena se explica por los versos que siguen en el texto de Propercio, en los que se alude al caballo Pegaso, también de poca ayuda en la huida: "(...) Ni aunque fueras llevado por el aire a lomos de Pegaso, ni aunque te moviera los pies el ala de Perseo, ni aunque te arrebataran los aires que las alas de tus tobillos cortaron, de nada te servirá el aéreo camino de Mercurio". Si bien omitió estos versos en la inscripción, el pintor se inspira en este pasaje y crea una imagen que viene a completar el texto. A continuación, insistiendo en la inutilidad de la huida, el poeta recalca el carácter implacable y amenazante de Cupido, a quien no conviene ofender: "Siempre el amor se cierne sobre tu cabeza, amenaza al enamorado, y abruma pesadamente la cerviz de personas libres. Centinela implacable, hace su guardia, y jamás sufrirá que levantes del suelo tus ojos

emblemática del Amor divino según Vaenius", Cuadernos de Arte e Iconografía de la Fundación Universitaria, 2, (1985), pp. 3-35.

${ }^{36}$ Catullus, Tibullus, Propertius, Antverpiae: ex officina Christophori Plantini, (1569).

37 Véanse las diferentes interpretaciones al respecto en Sextii Aurelii Propertii Carmina. The elegies of Propertius, with English notes by F.A. Paley, (London: John W. Parker and Son, 1853), p. 146.

${ }_{38} \mathrm{Mi}$ agradecimiento al Dr. Guillermo Fatás por su traducción de la inscripción en latín y sus valiosas observaciones (en comunicación escrita, 24/02/2017).

39 M. Gillet de Moivre, La vie et les amours de Properce, chevalier romain. Et la traduction en Prose \& en Vers François, de ce qu'il y a de plus intéressant dans ses Poésies, A Amsterdam: Chez Pierre Mortier, (1744), p. 10; Properce, Élégies: traduites dans toute leur intégrité, avec des notes interprétatives du Texte... par M. Delongchamps, tome II, A Paris: chez Duprat, (1802), p. 99. 
una vez cautivados. Y si le ofendieras, él es una divinidad implacable, con tal de ver que los ruegos siguen al instante" 40 .

El primer verso de la Elegía 30 ("Quo fugis ah demens?") figura también en un emblema del Théatre d'Amour según Jacques de Gheyn (ca. 1600), fuente para Daniel Heinsius en el emblema 22 de su Quaeris quid Amor (ca. 1601) (fig. 8). Ambos llevan el título Mon mal me suit (mi dolor me persigue) y la imagen de Cupido, dispuesto a partir, con las alas desplegadas y rienda en mano, a lomos de un caballo ${ }^{41}$. Esto confluye en la misma idea de la persecución del amor. Otto van Veen recurre de nuevo a estos versos en el emblema 12 de la Emblemata aliquot selectiora amatoria (1618). Añade el título Ille fuga silvas saltusque peragrat (él atraviesa en su huida bosques y montañas), tomado de la Eneida de Virgilio, y la imagen del amante que huye, flecha en pecho, perseguido por el amor en un paraje natural (fig. 9). No se obvia aquí, en cambio, la alusión a Pegaso de Propercio ("Quou figis, ah demens? Nulla est fuga: tu licet usque ad Tanaim figias, usque sequetur amor. Non si Pegaseo vecteris in aëria dorso, nec tibi si Persei moverit ala pedes"), añadiendo textos en neerlandés y francés.

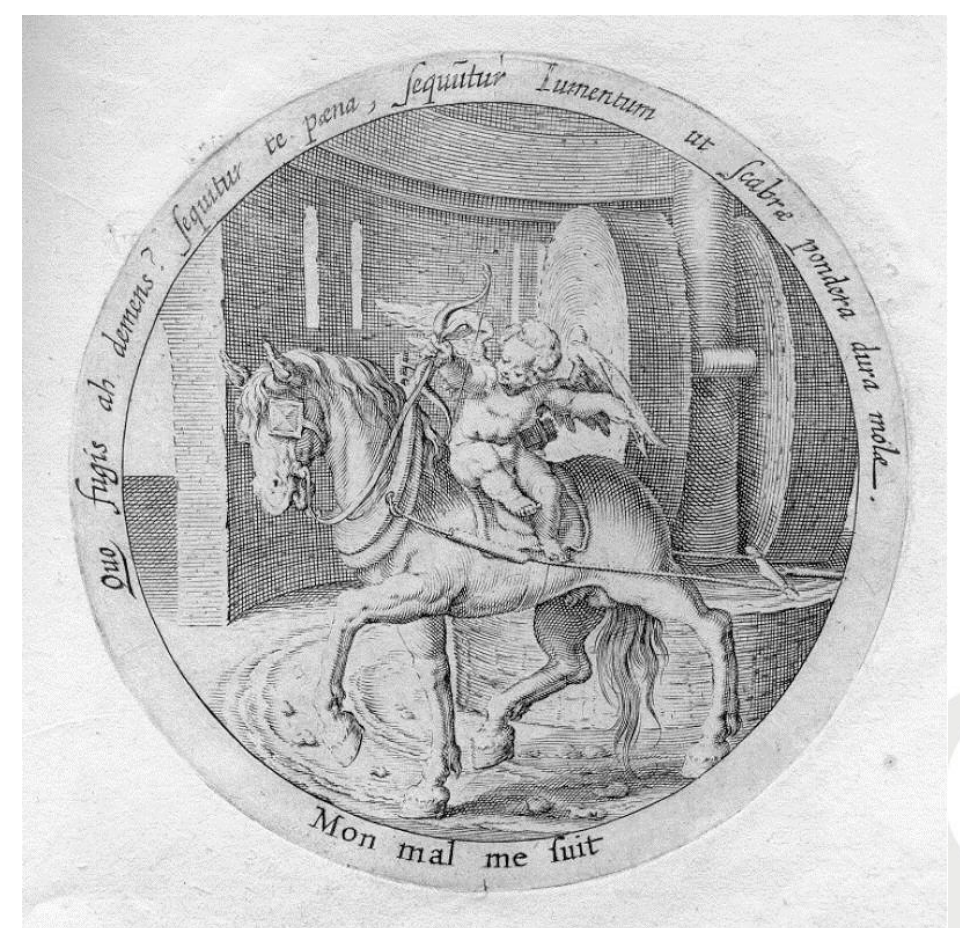

Fig. 8. Mon mal me suit. Emblema 22 del Quaeris quid Amor de Daniel Hensius (ca. 1601).

La proximidad con estas obras de emblemática invita a pensar en una fecha próxima para la pintura que tratamos, si bien no se observa en la carrera de

\footnotetext{
40 Propercio, Elegías, Libro II, XXX, 1-13, edición, traducción y notas de A. Tovar, Barcelona, (1963), p. 109.

41 "Quo fugis ah demens? sequitur te pæna, sequũtur / Iumentum ut scabræ pondera dura molæ". Londres, British Museum, Inv. 1889,0816.3.23. New Hollstein (Dutch \& Flemish) 329 (The De Gheyn family).
} 
Otto van Veen una línea evolutiva clara, pues parece haber conquistado y perpetuado su estilo sin notables variaciones. Con Ex Vino Sapienti Virtus, pintura que sirvió al grabado de la Emblemata Horatiana (1607), comparte el mismo espíritu ${ }^{42}$ : una tabla que debió contener en su origen una inscripción como la del lienzo que nos ocupa, según indica la banda rojiza que aún se observa, aunque mutilada, en el margen inferior. La misma banda alberga la inscripción de una Alegoría de gran tamaño del museo de Budapest ${ }^{43}$.

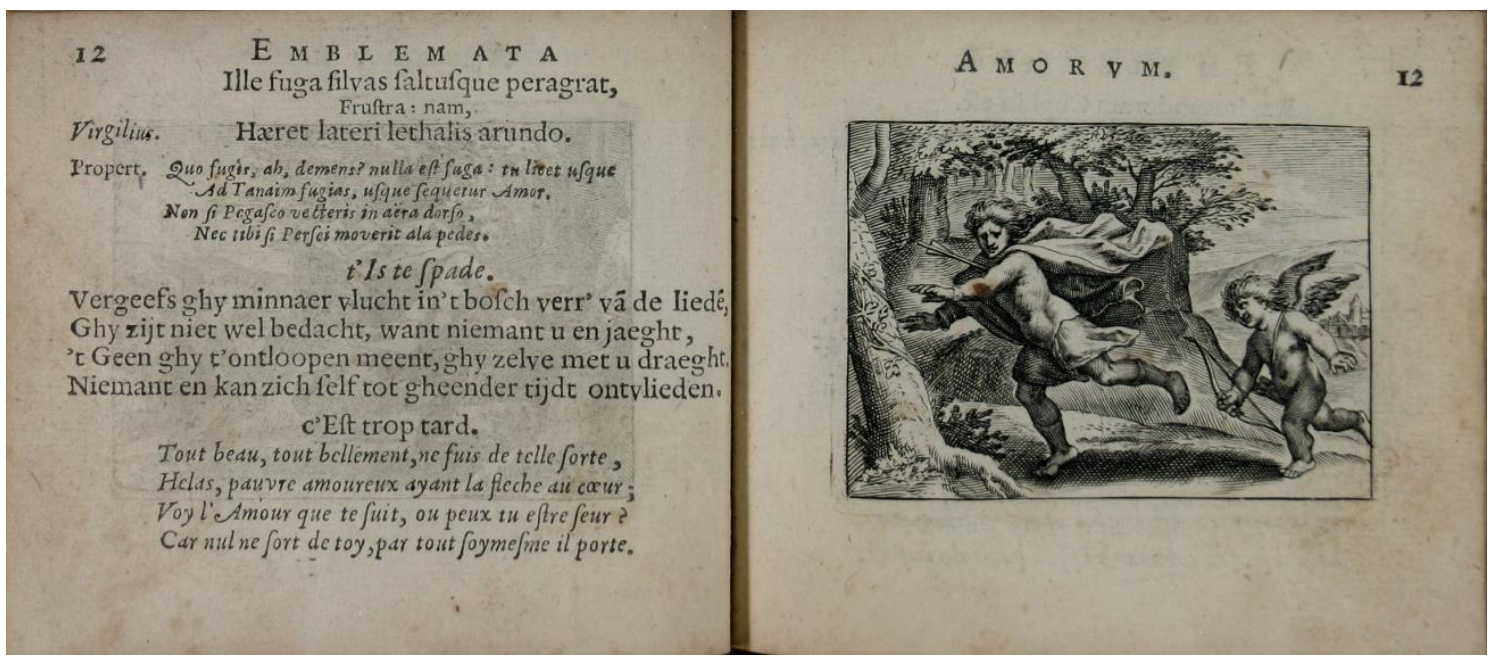

Fig. 9. Ille fuga silvas saltusque peragrat. Emblema 12 de la Emblemata aliquot selectiora amatoria de Otto van Veen (1618)

Es claro el mensaje que nuestro lienzo trasmite: más vale rendirse al amor que tratar de escapar de él, una actitud que participa de los ideales del Neoestoicismo del filólogo y humanista Justus Lipsius, a quien Rubens rendiría homenaje en el famoso lienzo de Los cuatro filósofos de la galería Pitti, al retratarlo en compañía de Jan Woverius, Philip Rubens y de sí mismo, bajo el busto de Séneca. Pero la amistad de Otto Vaenius con Lipsius data de años atrás. En carta de 1583 al humanista Dominicus Lampsonius, que fue maestro de Vaenius en Lieja, Lipsius señalaba la valía del joven Otto y alababa sus habilidades artísticas "para ilustrar muchas cosas de la Antigüedad"44. En el Album Amicorum de Otto Vaenius (1584), el erudito dejó constancia de su gran admiración por él, calificándolo de "cultissimae mentis"

\footnotetext{
42 Tabla, 92 x 71 cm. Colección privada. Ost, "Unbekannte Werke...", p. 288, fig. 7.

43 Lienzo, 154 × 224 cm. Inv. 80.16 Ildiko, "Drei Flämishe Allegorien...", p. 136, fig. 3. Lleva la inscripción "INVENI PORTVM, SPES ET FORTVNA VALETE, / NIL MIHI VOBISCVM LVDITE NVNC ALIOS", dístico que figura en una edición de 1569 de los epigramas de Jano Panonio y los Progymnasmata de Tomás Moro y William Lily (1518). Véase respecto a la historia del dístico, Iñigo Ruiz Arzalluz, "Un testimonio fantasma de Inveni portum, spes et fortuna valete», en Otium cum dignitate. Estudios en homenaje al profesor José Javier Iso Echegoyen, (ed.) J. A. Beltrán, A. Encuentra, G. Fontana, A. I. Magallón, R. Ma Marina, (Zaragoza: Universidad de Zaragoza, 2013), pp. 589-596.

44 "et cuius manus usui mihi esse poterat ad multa Antiquitatis ilustranda", Justus Lipsius, Epistolarum slectarum centuria miscellanea, Pars I, (Leiden: Plantin, 1586), p. 60, (ed. A. Gerlo, Bruxelles, 1978), II, p. 84.
} 
y asegurándole fidelidad en un ideal estoico de amistad ${ }^{45}$. En 1601 Lipsius le encargó una pintura (hoy perdida) con el suicidio ejemplar de Arria y Paetus, para colocar en la entrada de su casa junto a unos versos de la Epigrammata de Marcial ${ }^{46}$. El interés de Lipsius por las Elegías de Propercio se hace patente a lo largo de sus Antiquae Lectiones, manuscrito que entrega a Plantin en 1568, poco antes de partir a Roma, donde se dedicó a una edición de los escritos del poeta que no llegaría a completar ${ }^{47}$.

Con sabias alusiones a Propercio el lienzo refleja bien el gran conocimiento de la literatura clásica del pintor, que también ilustró a Horacio, a Ovidio y a otros clásicos como Tíbulo, Virgilio, Terencio y Séneca a los que cita en su amplio repertorio. Otto Vaenius se manifiesta aquí como el pictor doctus que es, concibiendo la pintura como erudición. No obstante, el carácter críptico se atenúa en esta imagen de fácil lectura. Se expresa el vínculo entre poesía y pintura, el principio horaciano de Ut pictura poesis que el humanismo elevó a categoría estética suprema y al que Vaenius alude en el prólogo de la Emblemata Horatiana.

Adquirida por el escultor Antonio Casamor (1907-1979), en cuya familia permanece por casi medio siglo, la pintura viene a sumarse a la escasa producción que del pintor se conserva en España ${ }^{48}$.

\footnotetext{
45 Jan van den Gheyn, Album Amicorum de Otto Vaenius, (Bruxelles, 1911), p. 55; Mark Morford, "Theatrum hodiernae vitae: Lipsius, Vaenius and the rebellion of Civillis", en Recreating Ancient History: Episodes from the Greek and Roman Past in the Arts and Literature of the Early Modern Period, (dir.) Karl A.E. Enenkel, Jan L. de Jong y Jeanine De Landtsheer, (Leiden: Brill, 2001), p. 59.

${ }^{46}$ Epistolarium Centuriae ad Belgas, Antwerpen: J. Moretus, (1602), III, carta 83. Elizabeth McGrath, Rubens Subjects from History. Corpus Rubenianum Ludwig Burchard, Part XIII, (London: Harvey Miller Publishers, 1997), I, p. 109, y Mark Morford, Stoics and Neostoics: Rubens and the Circle of Lipsius, (Princeton: Princeton University Press, 1991), p. 188.

47 Véanse los comentarios de Lipsius sobre las Elegías de Propercio. Justus Lipsius, "Antiquae Lectiones", en Opera Omnia, vol I, (Antuerpiae, 1637), p. 20, 39, 47, 56, 133. Sobre la carta de Lipsius de 1570 donde hace mención de la edición de Propercio que estaba preparando véase José Ruysschaert, "Le séjour de Juste Lipse à Rome (1568-1570) d'après ses Antiquae lectiones, et sa correspondance", Bulletin de I'Institut historique belge de Rome, 24 (1947-48), pp. 145-147; y Morford, Stoics and Neostoics, p. 33, nota 62.

${ }^{48}$ Véase la Santa Cena que conserva la Real Academia de Bellas Artes de San Fernando de Madrid (lienzo, 133 x 108 cm, inv. inv./cat.nr 0752), Alfonso Pérez Sánchez, Inventario de pinturas de la Real Academia de San Fernando, (Madrid, 1964), p. 69; Matías Díaz Padrón, La pintura flamenca del siglo XVII en España, Tesis Doctoral inédita, (Universidad Complutense, Madrid 1976), vol. III, pp. 1058-1059, fig. 475; una Piedad en colección privada de Madrid. Matías Díaz Padrón, Pedro Pablo Rubens. Exposición Homenaje, (Madrid, Palacio de Velázquez, 1977-1978), n 159; una Sagrada Familia en Vitoria. Ana Diéguez Rodríguez, "Una Sagrada familia de Otto van Veen del antiguo convento de Santa Clara de Orduña en Vitoria", Archivo Español de Arte, 83/332 (sept-oct. 2010), pp. 363-368; una serie de cobres en Briviesca. René Jesús Payo Hernanz y Ana Diéguez Rodríguez, "Regarding Otto van Veen's Coppers in the altarpiece of Our Lady of Rosary Chapel at the Hospital of Briviesca (Burgos)", Revue Belge d'Archéologie et $d^{\prime}$ 'Histoire de I'Art, (en prensa); y una serie de lienzos con Los Meses del año del museo del Prado en depósito en la Capitanía General de A Coruña. Matías Díaz Padrón, "La serie de los meses de Otto van Veen identificada en el Museo del Prado" (en prensa); Idem, "El humanismo de Otto van Veen para la serie de los meses del año en el Palacio del Buen Retiro", en Encrucijada de la palabra y la imagen simbólica, X Congreso Internacional de la Sociedad Española de Emblemática, del 17 al 19 de diciembre de 2015 .
} 
Bibliografía:

Bertini 1998: Giuseppe Bertini, "Otto van Veen, Cosimo Masi and the Art Market in Antwerp at the End of the Sixteenth Century", The Burlington Magazine, 140 (1998), pp. 119-120.

Branden 1883: Franz Joseph Peter van den Branden, Geschiedenis der Antwerpsche Schilderschool, (Antwerpen: Buschmann, 1883).

Branden 1883: Franz Joseph van den Branden, "Verzamelingen van schilderijen te Antwerpen", Antwerpsch Archievenblad, XXI (1883), pp.293472.

Burke y Cherry 1997: Marcus Burke y Peter Cherry, Collections of Paintings in Madrid 1601-1755 (Documents for the History of Collecting: Spanish Inventories 1), (Los Angeles: Maria L. Gilbert, The Provenance Index of the Getty Information Institute, 1997), 2 vols.

Canter 1669: Willem Canter(ed.), Catullus, Tibullus, Propertius, (Antverpiae: ex officina Christophori Plantini, 1569).

Denucé 1931: Jan Denucé, Exportation d'oeuvres d'art au XVII siècle à Anvers. La firme Forchoudt, (Anvers: De Sikkel, 1931).

Díaz Padrón (en prensa): Matías Díaz Padrón, "La serie de los meses de Otto van Veen identificada en el Museo del Prado".

Díaz Padrón 1976: Matías Díaz Padrón, La pintura flamenca del siglo XVII en España, Tesis Doctoral inédita, (Universidad Complutense, Madrid, 1976).

Díaz Padrón 2015: Matías, Díaz Padrón, Matías, "El humanismo de Otto van Veen para la serie de los meses del año en el Palacio del Buen Retiro", en Encrucijada de la palabra y la imagen simbólica, X Congreso Internacional de la Sociedad Española de Emblemática, del 17 al 19 de diciembre de 2015.

Diéguez Rodríguez 2010: Ana Diéguez Rodríguez, "Una Sagrada familia de Otto van Veen del antiguo convento de Santa Clara de Orduña en Vitoria", Archivo Español de Arte, 83/332 (sept-oct. 2010), pp. 363-368.

Duverger 1984-2009: Erik Duverger, Antwerpse kunstinventarissen uit de zeventiende eeuw, Brussel: Koninklijke Academie voor Wettenschappen, Letteren en Schone Kunsten van België, (Burssel, 1984-2009), 14 vols.

Forster 1981: Leonard W. Forster, Die Emblemata Horatiana des Otho Vaenius, (Wolfenbütteler Forschungen, Munich, 1981), pp. 117-128.

Gerards-Nelissen 1971: Inemie Gerards-Nelissen, "Otto van Veen's Emblemata Horatiana", Netherlands Quarterly for the History of Art, vol 5, 12, (1971), pp. 20-63.

Gheyn 1911: Joseph van den Gheyn, Album amicorum de Otto Venius. Reproduction intégrale en facsimilé avec introduction, transcripction, traductions, notes, (Bruxelles, 1911). 
Haute 2000: Bernadette van Haute, David III Ryckaert: A SeventeenthCentury Flemish Painter of Peasant Scenes, (Turnhout: Brepols, 2000).

Held 1953: Julius Held, "The authorship of three Paintings in Mons", Bulletin des Musées Royaux des Beaux Arts de Belgique, no 3 (1953), pp. 102-108.

Hoet y Terwesten 1770: Gerard Hoet y Pieter Terwesten, Catalogus of naamlyst van schilderyen met derzelver pryzen, zedert een langen reeks van jaaren zoo in Holland als op andere plaatzen in het openbaar verkogt, benevens een verzameling van lysten van verscheyden nog in wezen zynde cabinetten, ('s Gravenhage: Gaillard, 1770).

Hollstein 1949-2010: F.W.H. Hollstein, Dutch \& flemish etchings, engravings and woodcuts ca. 1450-1700, Amsterdam: Hertzberger, 1949-2010, 72 vols.

Ildiko 1991: Ember Ildiko, "Drei Flämische Allegorien im Museum der Bildende Künste in Budapest", Annales de la Galerie Nationale Hongroise, (1991), pp. 131-139.

Lipsius 1586 (ed. 1978): Justus Lipsius, Epistolarum slectarum centuria miscellanea, Pars I, (Leiden: Plantin, 1586, ed. A. Gerlo, Bruxelles, 1978).

Lipsius 1602: Justus Lipsius, Epistolarium Centuriae ad Belgas, (Antwerpen: J. Moretus, 1602).

Lipsius 1637: Justus Lipsius, "Antiquae Lectiones", en Opera Omnia, vol I, (Antuerpiae, 1637).

Madrid 1977-1978: Pedro Pablo Rubens. Exposición Homenaje, (dir.) Matías Díaz Padrón, (Madrid, Palacio de Velázquez, 1977-1978).

Maeyer 1955: Marcel de Maeyer, "Otto Vaenius en de tapihjtenreeks De Veldslagen van aartshertog Albrecht", Artes Textiles, II, (1955), pp. 105-111.

Markova 1986: V. E. Markova, Kartiny italjanskih masterov XIV-XVIII vekov iz muzeev USSR, (Moscú, 1986).

McGrath 1997: Elizabeth McGrath, Rubens Subjects from History. Corpus Rubenianum Ludwig Burchard, Part XIII, (London: Harvey Miller Publishers, 1997).

Moivre 1744: Gillet de Moivre, La vie et les amours de Properce, chevalier romain. Et la traduction en Prose \& en Vers François, de ce qu'il y a de plus intéressant dans ses Poésies, (A Amsterdam: Chez Pierre Mortier, 1744).

Morford 1991: Mark Morford, Stoics and Neostoics: Rubens and the Circle of Lipsius, Princeton: Princeton University Press, (1991).

Morford 2001: Mark Morford, "Theatrum hodiernae vitae: Lipsius, Vaenius and the rebellion of Civillis", en Recreating Ancient History: Episodes from the Greek and Roman Past in the Arts and Literature of the Early Modern Period, dir. Karl A.E. Enenkel, Jan L. de Jong y Jeanine De Landtsheer, (Leiden: Brill, 2001), pp. 57-74. 
Müller-Hofstede 1957: Justus Müller-Hofstede, "Zum Werke des Otto van Veen, 1590-1600", Bulletin des Musées Royaux des Beaux-Arts de Belgique, VI, (1957), pp. 127-174.

Müller-Hofstede 1971: Justus Müller-Hofstede, "Abraham Janssens: Zur Problematik des flämischen Caravaggismus", Jahrbuch der Berliner Museen, 13 (1971), pp. 208-303.

Müller-Hofstede 1976-1978: Justus Müller-Hofstede, "'Ut Pictura Poesis': Rubens und die humanistische Kunsttheorie", Gentse bijdragen tot de kunstgeschiedenis, 24, (1976-1978), pp. 171-189.

New Hollstein 1993-2015: The new Hollstein Dutch \& Flemish etchings, engravings and woodcuts 1450-170, 1993-2015, 30 vols.

Nueva York y Madrid 2007-2008: Tapestry in the Baroque: Threads of Splendor, ed. Thomas P. Campbell, (New York, Metropolitan Museum y Madrid, Palacio Real, 2007-2008).

Ost 2007: Hans Ost, "Unbekannte Werke von Otto van Veen", WallrafRichartz-Jahrbuch, LXVIII, (2007), pp. 279-294.

Payo Hernanz y Diéguez Rodríguez (en prensa): René Jesús Payo Hernanz y Ana Diéguez Rodríguez, "Regarding Otto van Veen's Coppers in the altarpiece of Our Lady of Rosary Chapel at the Hospital of Briviesca (Burgos)", Revue Belge d'Archéologie et d'Histoire de I'Art, (en prensa).

Pérez Sánchez 1964: Alfonso Pérez Sánchez, Inventario de pinturas de la Real Academia de San Fernando, (Madrid, 1964).

Properce ed. 1802: Properce, Élégies de Properce, traduites dans toute leur intégrité avec des notes interprétatives du texte... Nouvelle édition, revue, corrigée et considérablement augmentée par M. de Longchamps, (A Paris: chez Duprat Letellier et Cie, 1802), 2 vols.

Propercio ed. 1853 y 1872: Propercio, Sextii Aurelii Propertii Carmina. The elegies of Propertius, with English notes by F.A. Paley, (London: John W. Parker and Son, 1853), Second edition, carefully revised, (London: Bell and Daldy, 1872).

Propercio 1963: Propercio, Elegías, edición, traducción y notas de A. Tovar, (Barcelona, 1963).

Renger 2005: Konrad Renger, Staatsgalerie Neuburg an der Donau. Flämische Barockmalerei, (Munich, 2005).

Ruelens 1885: Charles Ruelens, "La vie de Rubens par Roger de Piles", Bulletin Rubens, II, (1885), pp. 157-175.

Ruiz Arzalluz 2013: Iñigo Ruiz Arzalluz, "Un testimonio fantasma de Inveni portum, spes et fortuna valete», en Otium cum dignitate. Estudios en homenaje al profesor José Javier Iso Echegoyen, ed. J. A. Beltrán, A. Encuentra, G. Fontana, A. I. Magallón, R. Ma Marina, (Zaragoza: Universidad de Zaragoza, 2013), pp. 589-596. 
Ruysschaert 1947-1948: José Ruysschaert, "Le séjour de Juste Lipse à Rome (1568-1570) d'après ses Antiquae lectiones, et sa correspondance", Bulletin de l'Institut historique belge de Rome, 24 (1947-1948), pp. 139-192.

Sebastián López 1983: Santiago Sebastián López, "Teatro moral de la vida humana, de Otto Vaenius: lectura y significado de los emblemas", Boletín del Museo e Instituto Camón Aznar, XIV, (1983), pp. 7-92.

Sebastián López 1985: Santiago Sebastián López, "La visión emblemática del Amor divino según Vaenius", Cuadernos de Arte e Iconografía de la Fundación Universitaria, 2, (1985), pp. 3-35.

Sebastián López 1985: Santiago Sebastián López, "Lectura crítica de la Amorum Emblemata de Otto Vaenius", Boletín del Museo e Instituto Camón Aznar, XXI, (1985), pp. 5-111.

Stighelen 1989: Katlijne van der Stighelen, "De (atelier-)bedrijvigheid van Andries Snellinck (1587-1653) en Co", Jaarboek van het Koninklijk Museum voor Schone Kunsten Antwerpen, (1989), pp. 303-341.

Vaenius 1607: Otto Vaenius, Quinti Horatii Flacci Emblemata, (Antwerpen: Hyeronimus Verdussen, 1607).

Vaenius 1608: Otto Vaenius, Amorum Emblemata, (Antwerpen: Hyeronimus Verdussen, 1608).

Vertue 1757: George Vertue, A Catalogue and Description of King Charles the First's capital collection, (London, 1757).

Vervaet 1977: Julien Vervaet, «Mannerism and the Italian influence in sixteenth-century Antwerp », Apollo, vol. CV, No.181, (March 1977), pp. 168175.

Vey 1962: Horst Vey, Die Zeichnungen Anton Van Dycks, Monographien des "Nationaal Centrum voor Plastische Kunsten van XVIde on XVII Eeuw", 1, (Brussels: Verlag Arcade, 1962), 2 vols.

Vlieghe 1981: Hans Vlieghe, "Rubens and Van Veen in contest: A marginal note", en Ars Auro Prior, Studia Ioani Bialostocki Sexagenario Dedicata, Varsovia, (1981), pp. 477-482.

Walch 1985: Nicole Walch, "Deux eaux-fortes anonymes en relation avec le tableau d'Otto van Veen Le Christ mort soutenu par un ange", en Francine de Nave (dir.), Liber Amicorum Leon Voet, (Antwerpen, 1985), pp. 629-643. 